\title{
IDENTIFICATION OF COLUMBIAN SHARP-TAILED GROUSE LEK SITES IN SOUTH CENTRAL WYOMING
}

\author{
Kurt T. Smith ${ }^{1,4}$, Jeffrey L. Beck ${ }^{1}$, Tony W. Mong ${ }^{2}$, and Frank C. Blomquist ${ }^{3}$
}

\begin{abstract}
CThe Columbian Sharp-tailed Grouse (Tympanuchus phasianellus columbianus; hereafter CSTG) occupies approximately $10 \%$ of its historic range and is a species of conservation concern in 7 U.S. states and British Columbia. Because little is known about the status of CSTG in Wyoming, we sought to model the relative probability of lek site occurrence within the known distribution of CSTG in the state to identify areas that contained previously undocumented lek sites. The proximity of nesting and brood-rearing habitats to leks advocates their use as a focus of conservation for prairie grouse, including CSTG. We modeled a resource selection function (RSF) to identify areas that were predicted to have a high probability of lek occurrence. In areas identified by the RSF, we searched for leks by conducting ground surveys and surveys from a fixed-wing airplane using aerial infrared (AIR) technology. We identified 6 previously undocumented CSTG leks through ground searches and 4 previously undocumented Greater Sage-Grouse (Centrocercus urophasianus) leks through AIR searches. Newly identified leks represented a $22 \%$ increase in the number of known CSTG leks in south central Wyoming. Our method not only improved knowledge of CSTG status in Wyoming, but may also improve identification of unknown lek sites and conservation of lekking habitat and additional reproductive habitats for prairie grouse species in other western states and provinces.
\end{abstract}

RESUMEN.-El urogallo de cola afilada ([CSTG]; Tympanuchus phasianellus columbianus) ocupa aproximadamente el $10 \%$ de su rango de distribución histórico y es una especie en peligro en 7 estados de los Estados Unidos y en British Columbia. Debido a que se conoce poco sobre la situación del CSTG en Wyoming, tratamos de modelar la probabilidad relativa de que surja un lek en un sitio conocido dentro de su distribución en el estado, para identificar áreas que contengan localizaciones de lek sin documentar. La proximidad de hábitats para anidación y de cría a los leks recomienda su uso como foco de conservación para el urogallo de las praderas, incluyendo CSTG. Modelamos una función de selección de recursos (RSF) para identificar las áreas pronosticadas como de alta probabilidad de casos de lek. Usando nuestro RSF, realizamos búsquedas de lek con Vuelos Aéreos con Infrarrojos (aerial infrared flights-AIR) con un avión de ala fija y búsquedas en el terreno. Identificamos 6 leks de CSTG sin documentar a través de búsquedas terrestres y 4 leks no registradas de urogallos (Centrocercus urophasianus). Los leks recientemente identificados representaron un aumento del $22 \%$ en el número de leks de CSTG conocidos en el centro-sur de Wyoming. Nuestro método no sólo mejoró el conocimiento de la situación de los CSTG en Wyoming, sino que puede resultar útil para mejorar la identificación de zonas con leks desconocidos y la conservación de estas zonas y otros hábitats de reproducción de las especies de urogallo de las praderas en otros estados y provincias del oeste.

The Columbian Sharp-tailed Grouse (Tympanuchus phasianellus columbianus; hereafter CSTG) is 1 of 6 subspecies of Sharp-tailed Grouse in North America (Johnsgard 1983). It currently occupies $<10 \%$ of its historic range, which formerly included parts of 9 U.S. states and British Columbia (Miller and Graul 1980, Stinson and Schroeder 2012), and has been petitioned for listing twice under the Endangered Species Act of 1973 (USDI 2000, 2006). In Wyoming, CSTG is found only in portions of southwestern Carbon County and is considered a species of greatest conservation need under Wyoming's wildlife action plan (Hoffman and Thomas 2007, Keinath et al. 2010).
Communal display, or lekking, by CSTG occurs during the breeding season when males gather to attract females for breeding (Johnsgard 1973). During this time when individuals are concentrated on lek sites, counts can be made for population monitoring and assessment. Leks are generally the focus of management efforts for Sharp-tailed Grouse subspecies because leks are associated with nesting and brood-rearing habitats, and provide a means for population surveys when individuals gather during annual breeding rituals (Giesen and Connelly 1993). Research indicates that the majority of female CSTG nesting and brood-rearing habitat is within

\footnotetext{
${ }^{1}$ Department of Ecosystem Science and Management, University of Wyoming, Laramie, WY 82071.

${ }^{2}$ Wyoming Game and Fish Department, Green River Regional Office, Green River, WY 82935.

${ }^{3}$ Bureau of Land Management, Rawlins Field Office, Rawlins, WY 82301.

4E-mail: ksmith94@uwyo.edu
} 
TABLE 1. Variables used in model selection analysis evaluating Columbian Sharp-tailed Grouse lek habitat selection in south central Wyoming.

\begin{tabular}{ll}
\hline Variable name & Description \\
\hline Environmental & Mean shrub cover (\%; USDA and USDI 2013) \\
Shrub_C & Mean shrub height (cm; USDA and USDI 2013) \\
Shrub_H & Proportion of big sagebrush land cover (Artemisia tridentata; USDA and USDI 2013) \\
BSage & Proportion of shrub land cover (USDA and USDI 2013) \\
Shrub & Proportion of forest land cover (USDA and USDI 2013) \\
Forest & Normalized difference vegetation index derived from NAIP imagery (USDA 2012) \\
NDVI & Soil sand (\%) from STATSGO soil data (Hanser et al. 2011) \\
Sand & Mean aspect derived from 30-m digital elevation map (DEM; USGS 2011) \\
Aspect & Ratio of local elevation (30-m, USGS 2011) to the average elevation at each analysis \\
RatDem & region. Values were multiplied by 1000 for ease of interpretation. \\
& Mean topographic ruggedness index (Riley et al. 1999) \\
TRI & Mean topographic wetness index (high values = increased soil moisture; Theobald 2007) \\
TWI & Surface disturbance area (bare ground resulting from vegetation removal): combination \\
Anthropogenic & of energy infrastructure (energy well sites, compressor sites), and human dwellings \\
DistBa & Euclidean distance (m) to nearest disturbance \\
EucDistBa &
\end{tabular}

$2.0 \mathrm{~km}$ of a lek (see Hoffman and Thomas 2007). For example, $85 \%$ of locations from radiomarked male and female CSTG from spring through fall were within $2.0 \mathrm{~km}$ of their lek of capture in northwestern Colorado (Boisvert et al. 2005). Lek sites are typically located in small openings in shrubland habitats that have greater topographic relief relative to the local surrounding area (Oedekoven 1985, Giesen and Connelly 1993); CSTG leks often occur in denser and taller shrub stands relative to other lekking grouse species such as Greater SageGrouse (Centrocercus urophasianus; Klott and Lindzey 1989). In Wyoming, CSTG breeding habitats within $1.0 \mathrm{~km}$ of a lek were characterized as having greater herbaceous (grass and forb) understory, with lower total shrub cover, but greater frequency of snowberry (Symphoricarpos sp.) relative to adjacent potential breeding habitats (Oedekoven 1985). Due to their relative vicinity to other seasonal habitats, leks represent an important habitat for CSTG populations. Disturbances during the lekking period (noise and human presence) reduced attendance of female Plains Sharptailed Grouse (T. p. jamesii) and may limit annual population productivity when limited breeding occurs at disturbed lek sites (Baydack and Hein 1987). Habitat loss and conversion of vegetation communities are major factors resulting in declining CSTG populations (Giesen and Connelly 1993). As such, protection of leks and breeding habitats is critical to ensure viable habitats for CSTG population persistence. Twenty-seven lek sites have been identified in south central Wyoming, but there are potentially other unknown leks in the area (T. Mong, personal communication, 2013). Grouse that visit these leks represent the only known CSTG breeding population in Wyoming.

We sought to (1) identify habitat characteristics that influenced lek site selection by CSTG, (2) identify areas that had a high probability of lek occurrence, and (3) locate previously undocumented leks in south central Wyoming. Our primary objective was thus centered on identifying, through modeling, the suite of variables and the scale at which those variables occurred at CSTG lek sites. Our second objective was to use this information to identify unknown Columbian Sharp-tailed Grouse leks within the species' distribution range in Wyoming. We used both aerial infrared (AIR) technology and ground surveys to search for new leks. AIR surveys have been used successfully to count CSTG at leks in southeastern Idaho (Gillette et al. 2015).

In a GIS framework, we compiled a suite of anthropogenic and environmental predictor variables on the basis of a priori information obtained from previous research on CSTG lek sites (e.g., Klott and Lindzey 1989; Table 1). We derived land cover and vegetation variables from the USDA Forest Service LANDFIRE Existing Vegetation Type raster data set to estimate shrub cover, shrub height, and land cover type for big sagebrush (Artemisia tridentata), shrub, and forest land cover. (30-m resolution; LANDFIRE 2013). To estimate total shrub cover and height, we reclassified 


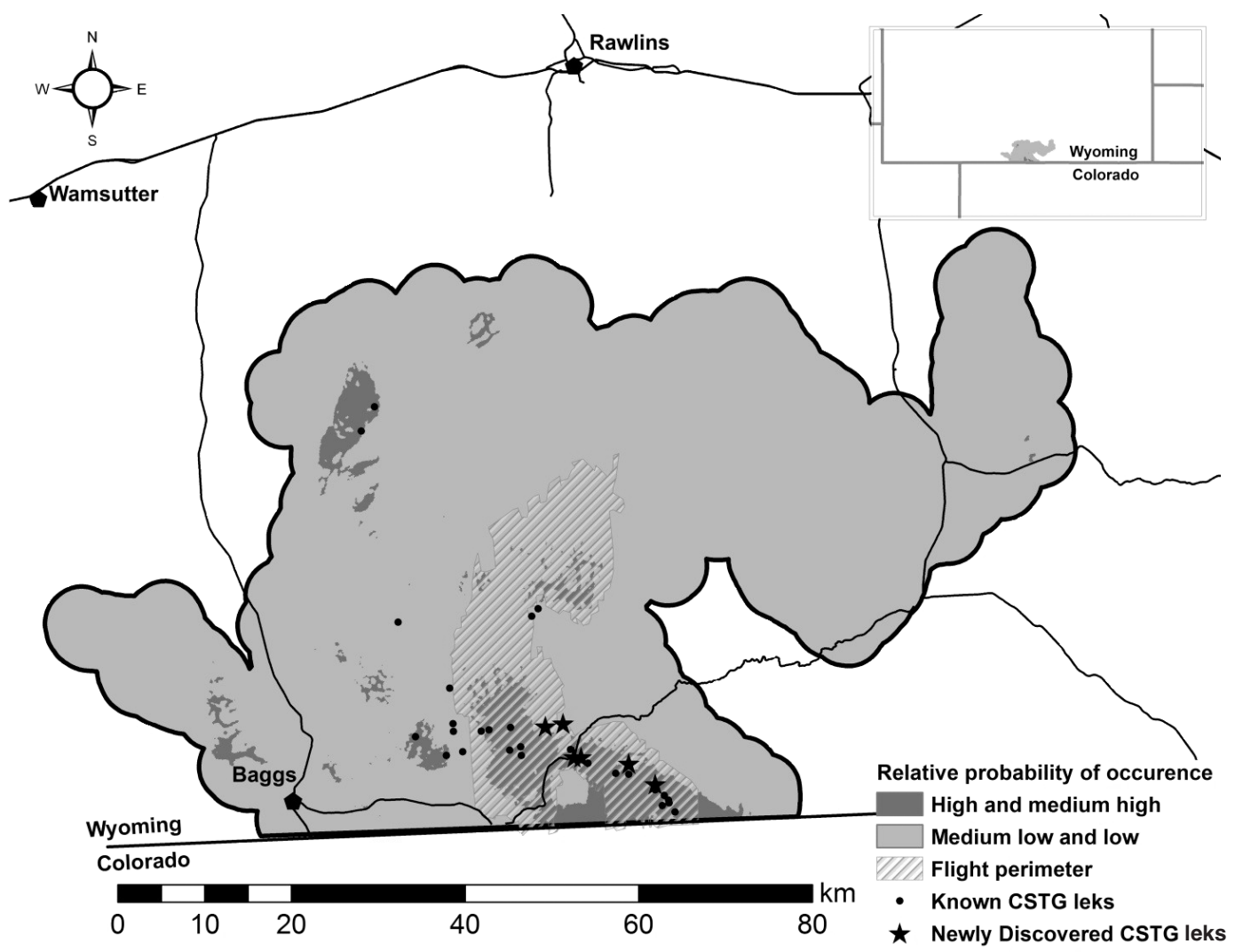

Fig. 1. Predicted probability of Columbian Sharp-tailed Grouse (CSTG) lek site occurrence in south central Wyoming. This map depicts a resource selection function that was binned into 2 quantiles of predicted relative probability of occurrence. Areas depicted in gray shades represent the highest (high and medium-high occurrence) and lowest (medium-low and low occurrence) predicted probability bins overlaid with previously known CSTG leks and newly discovered CSTG leks. All previously undocumented Sharp-tailed Grouse leks were documented from ground surveys in April and May 2015.

the LANDFIRE data set so that cover $(\%)$ and height $(\mathrm{cm})$ values were set to equal the midpoints of cover or height categories from the existing data (e.g., Scholer et al. 2014). We used a 30-m digital elevation map (DEM; USGS 2011) to calculate slope, a topographic ruggedness index (TRI; Riley et al. 1999), and a topographic wetness index (TWI; Sørensen et al. 2006). We followed the Wyoming Density Disturbance Calculation Tool (DDCT) protocol to create disturbance layers that quantified areas of bare ground resulting from removal of vegetation. Disturbances included energy infrastructure, roads, and nonenergyrelated disturbance such as human structures. We obtained road data for Wyoming from the U.S. Geological Survey (O’Donnell et al. 2014). We manually digitized remaining disturbances using 2012 NAIP imagery and buffered major and minor roads by $10 \mathrm{~m}$ and $3 \mathrm{~m}$, respectively.

We employed a use-availability design (Manly et al. 2002) to compare known CSTG leks to available locations constrained by the predicted distribution of CSTG in Wyoming developed previously from historical occurrence records (Fig. 1; Keinath et al. 2010). We randomly generated 40 times the number of known lek locations to adequately characterize available habitats (Northrup et al. 2013) across the predicted distribution $\left(4887 \mathrm{~km}^{2}\right)$ of CSTG in south central Wyoming (Keinath et al. 2010). Variables were evaluated at 3 spatial scales around used and available points: 0.25 $\mathrm{km}$ radii $\left(0.20 \mathrm{~km}^{2}\right), 0.50-\mathrm{km}$ radii $\left(0.79 \mathrm{~km}^{2}\right)$, and $2.0-\mathrm{km}$ radii $\left(12.57 \mathrm{~km}^{2}\right)$. We chose these scales to encompass the area immediately surrounding a lek, the daily movement of CSTG 
during the breeding season, and the distance within which the majority of females nest in proximity to leks (Giesen and Connelly 1993).

We used 2nd-order Akaike's information criterion $\left(\mathrm{AIC}_{c}\right)$ adjusted for small sample sizes to assess model support. For all scaledependent variables, we examined the spatial scales described above to determine the scale that was most correlated to CSTG lek occurrence by testing each variable scale individually and comparing $\mathrm{AIC}_{c}$ scores (Arnold 2010). For each variable, we retained the scale with the lowest $\mathrm{AIC}_{c}$ score corresponding to the greater predictive potential (Burnham and Anderson 2002). We removed unsupported variables based on whether $85 \%$ confidence intervals (CIs) around odds ratios included 1 (Hosmer and Lemeshow 2000, Arnold 2010). An odds ratio of 1 indicates no significant difference between used and available habitat units (Hosmer and Lemeshow 2000). We used variable screening to remove unsupported predictor variables, thereby reducing the likelihood of overfitting models in the model selection process (Burnham and Anderson 2002, Arnold 2010). For the remaining variables, we computed a Pearson's correlation matrix to test for multicollinearity among predictor variables and omitted one of each correlated variable when correlation coefficients $(r)$ were $\geq|0.6|$. We checked for stability and consistency of regression coefficient estimates when variables were moderately correlated $(|0.3| \leq r \leq|0.6|)$. If variables were correlated, the variable with the lowest $\mathrm{AIC}_{c}$ score was retained. We did not permit correlated variables to compete in the same model at any level of model selection. Following the initial variable screening procedure, we explored all variable combinations (Burnham and Anderson 2002) to determine the most predictive model. When a single top model was not evident based on the weight of evidence $\left(w_{i}\right)$, we model-averaged to estimate coefficients, standard errors, confidence intervals, and odds ratios for each variable in the candidate set (Burnham and Anderson 2002). We performed a 5-fold cross-validation to evaluate goodnessof-fit for our best model (Boyce et al. 2002). All statistical analyses were conducted with $\mathrm{R}$ statistical software (R Development Core Team 2011).

We mapped the final occurrence model with $30-\mathrm{m}$ pixel resolution across the study area. For interpretation, the final occurrence resource selection function (RSF) models were mapped with values rescaled between 0 and 1 (linear stretch; DeCesare et al. 2012) where 1 represented the highest and 0 represented the lowest predicted probability of occurrence. We distributed the predicted occurrence probabilities into 2 quartiles on the basis of percentile breaks in predicted probabilities (Fig. 1; Sawyer et al. 2006). We used the predictive surface map to conduct aerial infrared flights (cooled thermal imager positioned in a fixed-wing aircraft; Owyhee Air, Murphy, ID). During the morning hours (5:30-8:30) on 13, 14, and 19 April, pilots conducted AIR flights following standard survey protocols (J. Romero, Owyhee Air, personal communication, 2015) across approximately $572 \mathrm{~km}^{2}$ (surveying approximately 200 of the $320 \mathrm{~km}^{2}$ that were predicted to have high or medium-high CSTG lek occurrence, and $372 \mathrm{~km}^{2}$ that were predicted to have medium-low to low occurrence; Fig. 1). AIR flights were performed in predicted high and low lek occurrence areas to validate our models. That is, we expected that more previously undocumented leks would be located in predicted high or medium-high CSTG lek occurrence than in predicted medium-low to low lek occurrence areas. During 13-17 April, and 30 April-4 May 2015, we performed ground searches opportunistically in areas with limited access (i.e., few roads) during morning hours (5:30-9:00). Ground searches consisted of a single observer walking and listening for CSTG vocalizations. These efforts supplemented aerial infrared lek searches, and were not considered a comprehensive coverage of potential lekking sites. We considered a lek to be independent and newly discovered if it was $\geq 0.80 \mathrm{~km}$ from previously documented lek locations. This designation was to avoid the possibility that some leks occur in complexes and change locations on a yearly basis (Schroeder et al. 2000).

Competitive models that best explained CSTG lek locations contained 7 predictor variables across 3 spatial scales. Nineteen models were competitive with the top model $\left(\Delta \mathrm{AIC}_{c}=0.37-4.49\right)$ and were retained for model selection. Model-averaging indicated that the 95\% confidence interval for the odds ratio estimate of Shrub_H $\mathrm{H}_{2000 \mathrm{~m}}$, RatDem ${ }_{500 \mathrm{~m}}$, $\mathrm{TRI}_{2000 \mathrm{~m}}$, and EucDistBa $250 \mathrm{~m}$ overlapped 1 (Table 2); therefore, we considered those 
TABLE 2. Parameter estimates and odds ratios for variables that were included in the top model depicting Columbian Sharp-tailed Grouse lek occurrence in south central Wyoming, 2015.

\begin{tabular}{|c|c|c|c|c|c|c|}
\hline \multirow[b]{2}{*}{ Parameter } & \multirow[b]{2}{*}{ Estimate } & \multicolumn{2}{|c|}{$95 \% \mathrm{CI}$} & \multirow{2}{*}{$\begin{array}{c}\text { Odds } \\
\text { ratio }\end{array}$} & \multicolumn{2}{|c|}{$95 \% \mathrm{CI}$} \\
\hline & & Lower & Upper & & Lower & Upper \\
\hline Shrub_C ${ }_{2000 \mathrm{~m}}$ & 0.153 & 0.080 & 0.227 & 1.166 & 1.083 & 1.255 \\
\hline Shrub_- ${ }_{2000 \mathrm{~m}}$ & 0.024 & -0.009 & 0.057 & 1.024 & 0.991 & 1.059 \\
\hline Bsage $_{2000 \mathrm{~m}}$ & -4.104 & -5.747 & -2.462 & 0.017 & 0.003 & 0.085 \\
\hline Sand $_{250 \mathrm{~m}}$ & 0.046 & 0.009 & 0.084 & 1.047 & 1.009 & 1.088 \\
\hline RatDem $_{500 \mathrm{~m}}$ & 0.056 & -0.018 & 0.129 & 1.057 & 0.982 & 1.138 \\
\hline $\mathrm{TRI}_{2000 \mathrm{~m}}$ & -0.018 & -0.058 & 0.023 & 0.983 & 0.943 & 1.023 \\
\hline EucDistBa ${ }_{250 \mathrm{~m}}$ & -0.006 & -0.012 & 0.000 & 0.994 & 0.988 & 1.000 \\
\hline
\end{tabular}

variables to be less informative than Shrub_C $2000 \mathrm{~m}$, BSage $_{2000 \mathrm{~m}}$, and $\mathrm{Sand}_{250 \mathrm{~m}}$. A $10 \%$ increase in shrub cover within $2000 \mathrm{~m}$ resulted in an increase in relative probability of lek site presence by approximately $86.7 \%$. For every $1 \%$ increase in sand soil content within $250 \mathrm{~m}$, the relative probability of a lek increased by approximately $58.9 \%$. An increase in $10 \%$ of the proportion of land cover dominated by big sagebrush habitats within $2000 \mathrm{~m}$ decreased the relative probability of a lek site by $32.7 \%$. The interpretations of change in odds ratios (selection probabilities) per unit change in variables were calculated as the median change in odds bound by the range of values for that variable, with other variables in the model held at their mean values. Cross-validation indicated that our best model was a strong, positive predictor of CSTG lek occurrence $\left(r_{s}=0.97\right)$.

Through ground surveys, we located 6 previously undocumented CSTG leks (Fig. 1.). Four of the 6 leks identified occurred in areas that were predicted to have a high probability of lek occurrence. These new leks increased the number of known CSTG leks in south central Wyoming by $22 \%$. No CSTG leks were located with AIR; however, AIR searches identified 4 potential Greater SageGrouse leks that were previously undocumented; 1 lek was subsequently verified from the ground.

Our research formed initial improvement in the knowledge of CSTG population status and habitat characteristics in south central Wyoming. This work may lead to further investigations that assess seasonal habitat selection patterns of CSTG and the potential consequences of alterations to habitats used by CSTG populations. Most importantly, this analysis provided a better understanding of CSTG abundance and population status in south central Wyoming, which is fundamental to the conservation of CSTG in this region.

Our research not only provides local managers with identification of additional CSTG leks in south central Wyoming, but also provides a similar method to improve identification of unknown lek sites for prairie grouse species in other western states and provinces. Similar methods have been used to identify lekking locations for Greater Prairie Chickens (Tympanuchus cupido) in Kansas (Gregory et al. 2011). Given the high costs of locating new leks (Gillette et al. 2015), this framework provides a method to refine search areas to identify the relative probability of occurrence of lekking habitats, thereby potentially maximizing the use of limited financial resources for lek identification and subsequent monitoring. Unfortunately, we were unable to locate previously undocumented CSTG leks with AIR. Gillette et al. (2015) found no differences in counts of 25 CSTG leks between groundbased and AIR methods in Idaho, suggesting AIR is a useful method for estimating CSTG lek attendance. Through conjecture, we predicted that the high precision of AIR for counting CSTG leks would make AIR equally useful for locating unknown lek sites. However, the majority of leks located in the study area of Gillette et al. (2015) consisted of Conservation Reserve Program (CRP) lands interspersed with mixed shrub communities. Most known leks in our study area occurred in relatively tall stands of dense shrub communities that potentially contain more escape cover for CSTG. Therefore, it is likely that differences in plant communities influence the ability of AIR to identify CSTG concentrations in our study area, where very dense shrub communities may limit the application of AIR.

CSTG and Greater Sage-Grouse co-occur in our study area (Klott and Lindzey 1989, 1990); 
by searching for CSTG leks, we simultaneously located previously unknown sage-grouse leks. The additional benefit of locating new sagegrouse leks may be realized in other states (Colorado, Idaho, Nevada, Oregon, Utah, and Washington) where the 2 species co-occur (Hoffman and Thomas 2007).

We thank T. Christiansen for providing logistical support for this research. K. Lawson assisted with spatial analysis. The Wyoming Game and Fish Department and the University of Wyoming Biodiversity Institute provided funding for our research. We thank Owyhee Air Research, Murphy, Idaho, for AIR flights. This material is based on work supported by the University of Wyoming, Wyoming Reclamation and Restoration Center through its graduate assistantship program.

\section{Literature Cited}

ARNOLD, T.W. 2010. Uninformative parameters and model selection using Akaike's information criterion. Journal of Wildlife Management 74:1175-1178.

BAYDACK, R.K., AND D.A. HeIn. 1987. Tolerance of Sharptailed Grouse to lek disturbance. Wildlife Society Bulletin 15:535-539.

Boisvert, J.H., R.W. Hoffman, and K.P. Reese. 2005. Home range and seasonal movements of Columbian Sharp-tailed Grouse associated with Conservation Reserve Program and mine reclamation. Western North American Naturalist 65:36-44.

Boyce, M.S., P.R. Vernier, S.E. Nielson, and F.K.A. SCHMiEGELOW. 2002. Evaluating resource selection functions. Ecological Modeling 157:281-300.

Burnham, K.P., AND D.R. ANDERSON. 2002. Model selection and inference: a practical information-theoretic approach. 2nd edition. Springer-Verlag, New York, NY.

DeCesare, N.J., M. Hebblewhite, F. Schmiegelow, D. Hervieux, G.J. McDermid, L. Neufeld, M. Bradley, J. Whittington, K.G. Smith, L.E. Morgantini, ET aL. 2012. Transcending scale dependence in identifying habitat with resource selection functions. Ecological Applications 22:1068-1083.

Giesen, K.M., And J.W. Connelly. 1993. Guidelines for management of Columbian Sharp-tailed Grouse habitats. Wildlife Society Bulletin 21:325-333.

Gillette, G.L., K.P. Reese, J.W. Connelly, C.J. Colt, AND J.M. KNetTER. 2015. Evaluating the potential of aerial infrared as a lek count method for prairie grouse. Journal of Fish and Wildlife Management 6: 486-497.

Gregory, A.J., L.B. McNew, T.J. Prebyl, S.M. Wisely, and B.K. Sandercock. 2011. Hierarchical modeling of lek habitats of Greater Prairie-Chickens. Studies in Avian Biology 39:21-32.

Hanser, S.E., M. Leu, S.T. Knick, and C.L. Aldridge. 2011. Sagebrush ecosystem conservation and management: ecoregional assessment tools and models for the Wyoming Basins. Allen Press, Lawrence, KS. $409 \mathrm{pp}$.
Hoffman, R.W., And A.E. Thomas. 2007. Columbian Sharptailed Grouse (Tympanuchus phasianellus columbianus): a technical conservation assessment. USDA Forest Service, Rocky Mountain Region, Denver, CO.

Hosmer, D.W., And S. Lemeshow. 2000. Applied logistic regression. 2nd edition. John Wiley \& Sons, New York, NY.

JoHnSGaRD, P.A. 1973. Grouse and quails of North America. University of Nebraska Press, Lincoln, NE.

JohnsGard, P.A. 1983. Grouse of the world. University of Nebraska Press, Lincoln, NE.

Keinath, D.A., M.A. Andersen, and G.P. Beauvis. 2010. Range maps for Wyoming's species of greatest conservation need. Report prepared for the Wyoming Game and Fish Department by the Wyoming Natural Diversity Database, Laramie, WY. 19 January 2010.

KLotT, J.H., AND F.G. Lindzey. 1989. Comparison of sage grouse and Sharp-tailed Grouse leks in south central Wyoming. Great Basin Naturalist 49:275-277.

KLOTt, J.H., AND F.G. Lindzey. 1990. Brood habitats of sympatric sage grouse and Columbian Sharp-tailed Grouse in Wyoming. Journal of Wildlife Management 54:84-88.

Manly, B.F., L.L. McDonald, D.L. Thomas, T.L. McDonald, and W.P. ERICKson. 2002. Resource selection by animals: statistical design and analysis for field studies. Chapman and Hall, London, UK

Miller, G.C., AND W.D. Graul. 1980. Status of Sharptailed Grouse in North America. Pages 18-28 in P.A. Vohs Jr. and F.L. Knopf, editors, Proceedings of the Prairie Grouse Symposium, Oklahoma State University, Stillwater, OK

Northrup, J.M., M.B. Hooten, C.R. Anderson, and G. WitTEMyer. 2013. Practical guidance on characterizing availability in resource selection functions under a use-availability design. Ecology 94:1456-1463.

O’Donnell, M.S., T.S. Fancher, A.T. Freeman, A.E. Ziegler, Z.H. Bowen, and C.L. Aldridge. 2014. Large scale Wyoming transportation data-a resource planning tool. U.S. Geological Survey Data Series 821. 21pp. http://dx.doi.org/10.3133/ds821

Oedekoven, O.O. 1985. Columbian Sharp-tailed Grouse population distribution and habitat use in south central Wyoming. Master's thesis, University of Wyoming, Laramie, WY.

R Development Core Team. 2011. R: environment and language for statistical computing. Version 3.0.0. R Foundation for Statistical Computing, Vienna, Austria.

Riley, S.J., S.D. Degloria, and R. Elliot. 1999. A terrain ruggedness index that quantifies topographic heterogeneity. Intermountain Journal of Sciences 5:1-4.

SAWyer, H., R.M. Nielson, F. Linzey, AND L.L. MCDONALD. 2006. Winter habitat selection of mule deer before and during development of a natural gas field. Journal of Wildlife Management 70:396-403.

Scholer, M.N., M. LeU, AND J.R. BelthofF. 2014. Factors associated with Flammulated Owl and Northern Saw-whet Owl occupancy in southern Idaho. Journal of Raptor Research 48:128-141.

Schroeder, M.A., D.W. Hays, M.A. Murphy, and D.J. Pierce. 2000. Changes in the distribution and abundance of Columbian Sharp-tailed Grouse in Washington. Northwestern Naturalist 81:95-103.

Sørensen, R., U. Zinko, And J. Seibert. 2006. On the calculation of the topographic wetness index: evaluation of different methods based on field observations. Hydrology and Earth System Sciences 10:101-112. 
Stinson, D.W., And M.A. Schroeder. 2012. Washington State recovery plan for the Columbian Sharp-tailed Grouse. Washington Department of Fish and Wildlife, Olympia, WA

TheobaLD, D.M. 2007. LCap v1.0: landscape connectivity and pattern tools for ArcGIS. Colorado State University, Fort Collins, CO.

[USDA] United States Department of Agriculture. 2012. NAIP imagery-1m (RGBIR)-Wyoming. USDA Farm Service Agency Aerial Photography Field Office, Salt Lake City, UT.

[USDA and USDI] United States Department of AgRICulture and United States Department of the INTERIOR. 2013. LANDFIRE: landscape fire and resource management planning tools. http://www landfire.gov
[USDI] United States Department of the Interior. 2000. Endangered and threatened wildlife and plants; 12-month finding for a petition to list the Columbian Sharp-tailed Grouse as threatened. Federal Register 65:60391-60596.

[USDI] United States Department of the Interior. 2006. Endangered and threatened wildlife and plants; 90-day finding on a petition to list the Columbian Sharp-tailed Grouse as threatened or endangered. Federal Register 71:67318-67325.

[USGS] United States Geological Survey. 2011. Seamless Data Warehouse. http://seamless.usgs.gov/

Received 11 September 2015 Accepted 1 December 2015 